\title{
Editorial: Psychology — tracing the SAJP's progress in helping shape the future of psychology in South Africa
}

\author{
Kobus Maree \\ University of Pretoria, Pretoria, South Africa \\ kobus.maree@up.ac.za
}

It is hard to believe that we have reached the end of the first term of the year already. As mentioned on previous occasions, the $S A J P$ 's success can be attributed to many factors including the exceptional support from the editorial board, which, among other things, has helped us reduce the backlog of articles. Only a few articles currently in our offices have been under review for longer than five months and even fewer for longer than four months.

We have finalised Issue 40(2) (June, 2010) and are in the process of compiling Issue 40(3). The core editorial staff - PsySSA president, Kopano Ratele, consulting editor, Anthony Pillay, consulting editor: statistics, Tyrone Pretorius, copy editors, Willy Nel and Martin Strous, and publishing editor, Erna Kinsey - have combined well to maintain on-time delivery and the smooth running of the journal by dealing timeously with potential problems.

After consulting global experts on ways to heighten the impact of the $S A J P$, we can report that we are particularly interested in reviewing articles covering meta-analyses of previous research/ theoretical points of view and articles on the standardisation of new assessment instruments. Articles that cast new light on 'old' issues (articles dealing with issues of the day in an innovative, creative manner) will also be most welcome.

As always, an imposing array of scholars has contributed to Issue 40(1). Interested readers will be given insight into research endeavours in a number of psychological subfields, into progress made in terms of racial integration in training institutions over the past few years, and into the consequences of and contributory factors in teen-aged pregnancy. Other topics covered are the impact of stress on human behaviour and personality, the merit of Rasch modelling methods when constructing and using interval scale measures, and whether emotional intelligence should be considered an integral part of positive psychology. The various authors also investigate the psychological impact of child sexual abuse, the correlation, if any, between limited mental health knowledge and attitudes toward mental illness and the seeking of psychological treatment, and the training of the personnel and the efficacy of psychological services rendered by registered counsellors The role of language skills and social interaction in the development of social understanding as well as a strategy to deal with the negative self-concept and unhealthy eating habits of adolescents are also examined.

Readers will have noted that we always attempt to publish articles dealing with issues that cut across the different subdisciplines of psychology (clinical, counselling, educational and research). We are particularly interested in themes that provide a starting point for interpreting psychological reality. It was especially heartening to receive, for example, a longitudinal study on teen-aged pregnancy in which the contributory factors are tackled head on in an attempt to better understand and manage the phenomenon. The contributions, as usual, reflect research conducted in all three research paradigms (qualitative, quantitative, and multi-method).

Boasting a number of exceptional international contributions by leading global scholars, the list of contributions is diverse in terms of institution, gender and international profile. As only one article in this issue was authored by emerging black authors, we wish to repeat our invitation to established as well as emerging black researchers to use the $S A J P$ as an outlet for their publications. We remain committed to capacity building and supporting black scholarship.

We wish to thank all colleagues who responded to our call for readers to review articles. The response was heartening. 
Lastly, readers are requested to forward proposals for future guest issues to the editor. I will then submit them to the editorial board for ranking, after which a decision will be taken.

The question is often asked whether tertiary (and other) training institutions have made progress, have remained static or have regressed in terms of racial integration over the past number of years. The leading article is entitled Understanding the seating patterns in a residence dining hall: a longitudinal study of intergroup contact. The authors, Schrieff, Tredoux, Finchilescu and Dixon (2010), implemented a combination of observational and questionnaire methods to investigate interracial contact in the mentioned context focusing specifically on the seating patterns. The results revealed extensive informal division by race and thus high levels of racial segregation despite the fact that the students had had ample opportunities for regular contact. Moreover, the students' preference for sitting with same-race peers remained relatively constant across the study period. As was the case in previous studies of a similar nature, the students reported that seating choices pointed to wider friendship patterns as well as the importance of eating with people with whom they felt 'comfortable'. Readers can decide whether satisfactory progress has been made in this regard since 1994.

Concerns at national level about the consequences of and the contributory factors in teen-aged pregnancy have escalated over the past few years. In the second contribution, A decade later: followup review of South African research on the consequences of and contributory factors in teen-aged pregnancy, Macleod and Tracey review South African research conducted during the past 10 years on teen-aged pregnancy. They focus on the rates of teen-aged pregnancy, the intentionality pregnancy, the disruption of schooling, health issues, consequences for the children, welfare concerns, knowledge and use of contraception, timing of sexual debut, age of partner, coercive sexual relations, cultural factors and health service provision. The authors compare reviews on the same subject in the SAJP a decade ago and conclude that, in general and mostly as a result of representative national and local surveys, the breadth of the data available has improved. Nuances surrounding particular issues are also scrutinised and analysed more satisfactorily today.

The impact of stress on various facets of human behaviour and personality is regularly investigated. It is interesting to note that Jacobs and Nadel's (1985, in Thomas, Laurance, Nadel, \& Jacobs, 2010) prediction that the physiological effects of an acute stressor disrupt a neurological system underlying cognitive-map (CM) guided navigation, but leave intact systems underlying landmark (LM) guided navigation has been confirmed only partially (Conrad et al., 2003; Schwabe et al., 2007, in Thomas, Laurance, Nadel, \&. Jacobs, 2010). Likewise, gender differences in the relations between acute stress and spatial navigation have not been investigated satisfactorily. This, despite the fact that stress affects verbal memory and decision-making performance of males and females differently. In the third contribution, Stress-induced impairment of spatial navigation in females, Thomas, Laurance, Nadel, and Jacobs (2010) deal with various stress-related issues. They administered the Trier Social Stress Test (TSST) to 15 healthy undergraduates to examine the effects of acute stress on cognitive map (CM) and landmark (LM) guided navigation in men and women and to a demographically matched control group of 14 undergraduates. They concluded that exposure to the TSST disrupted CM-guided (but not LM-guided) navigation in women but affected neither in men. Their findings give rise to novel views on the relative vulnerability of women to the acute psychosocial stress of CMbased navigation.

Questions have been raised about the suitability of Rasch modelling methods when constructing and using interval scale measures of, for example, temperament styles from forced choice data. In the first international contribution, Temperament styles in Zimbabwean early adolescents: A Rasch measurement model analysis, Mpofu, Oakland and Gwirayi (2010) report on an investigation (employing Rasch analysis methods) into the structure of temperament styles of Zimbabwean early adolescents who had completed the Student Styles Questionnaire (SSQ). Whereas analysis of the standardised residuals yielded unidimensional latent temperament variables for extroversion-introversion (EI), practical-imaginative (PM), thinking-feeling (TF) and organised-flexible (OL) styles, 
higher endorsements were found for extroversion (E) than introversion (I) styles, for practical (P) than imaginative (M) styles, for feeling (F) than thinking (T) styles and for organised (O) than flexible (L) styles. The authors conclude that Rasch modelling methods may have merit when constructing and using interval scale measures of temperament styles from forced choice data.

The constructs 'emotional intelligence' (EI) and 'positive psychology' are two of the most visible and popular areas of research in psychology today. In the second international contribution, Emotional intelligence: an integral part of positive psychology, Bar-On (2010) discusses how both constructs have been described, defined and conceptualised over the past decade and concludes that EI should be considered an integral part of positive psychology.

The psychological impact of child sexual abuse has been widely researched, and interest in therapeutic approaches that can be applied to sexually abused children has grown accordingly. The sixth contribution, Group art therapy with sexually abused girls, by Pretorius and Pfeifer, adds to the body of literature in this field. The authors report on an evaluation of an existential-humanistic, Gestalt, client-centred and abuse-focused group art therapy intervention aimed at reducing depression, anxiety, sexual trauma and low self-esteem among sexually abused girls aged eight to 11 years.. Employing the Solomon four-group design to investigate the efficacy of the intervention, the authors conclude that the experimental groups improved significantly compared to the control groups with regard to anxiety and depression.

Inaccurate and limited mental health knowledge can result in negative attitudes toward mental illness and the seeking of psychological treatment. Samouilhan and Seabi (2010) deal with this issue in the seventh contribution, University students' beliefs about the causes and treatments of mental illness. In an attempt to investigate university students' beliefs about the aetiology and treatment of mental illness, 112 students from the faculties of Law and Engineering of a large South African university were polled on the topic. The authors found that the participants believed that stressful events led to depression and substance abuse, that chemical imbalance caused schizophrenia and that negative social factors triggered anorexia nervosa. Professional psychological intervention was considered by $48 \%$ of the participants as the best overall treatment for the four disorders and, like other researchers before them, the authors discovered a number of significant relationships between aetiological and treatment beliefs.

Ever since its inception, the registration category Registered Counsellor has been debated widely in terms of the training and efficacy of its practitioners. Despite the existence of the category for several years, little evidence exists that it is fulfilling the purpose for which it was created, namely to supply psychological services at a primary health care level. Elkonin and Sandison's (2010) article Perceptions of registered counsellor efficacy is a welcome addition to the limited body of literature on the roles that registered counsellors play in their practicum placements. Contrary to what is often alleged, the authors report positive findings on the perceived value of registered counsellors across a variety of settings.

In her article, Comparing native signing, late-signing and orally trained deaf children's 'theory of mind' abilities, Van Staden (2010) discusses the role of language skills and social interaction in social understanding and 'theory of mind' development. She locates herself within social constructivism as a conceptual framework for theorising about 'theory of mind' development in relation to language acquisition, social interaction and the assessment of 'false-belief'. In addition, she demonstrates the advantage sign language may offer in the early years of a deaf child's life by comparing the performance of native signing deaf children with deaf parents with late signing and orally trained deaf children of hearing parents on different 'false-belief' tasks.

Many researchers have shown interest in the possible link between the negative self-concept and unhealthy eating habits of adolescents and have devised numerous intervention strategies to resolve the problem. In their article, An interactionist model of self-concept and eating habits, Lessing and De Beer (2010) report on a qualitative investigation into this issue involving a sample nine adolescents with unhealthy eating habits and problematic self-concepts. They conclude that an Interactionist 
Model of Self-concept and Eating Habits could be useful as a therapeutic instrument in a psychoeducational intervention programme for such adolescents.

Lastly: It is with great sadness that we report the passing of Ronald Charles Albino (1916-2009), founding editor of The South African Journal of Psychology. This issue of the SAJP ends with an obituary on this exceptional scholar by Margaret Daymond.

Please submit your contributions to help us stimulate debate on psychology in South Africa, Africa and abroad and to expand the existing network of scholars in South Africa, in the SADC region and in the rest of the world. Should you have and ideas for improving the $S A J P$, please feel free to contact me personally (kobus.maree@up.ac.za). Your feedback is important to us and will help shape the future direction of the journal.

We conclude by thanking everybody involved in the editorial and publishing process for their contributions. Our associate editors, Willy Nel and Martin Strous, as well as our consulting editor, Anthony Pillay, our consulting editor: statistics, Tyrone Pretorius, our publishing editor, Erna Kinsey, and our editorial assistant, Temi Nkambule, deserve a special word of thanks for their help and dedication. We also wish to request colleagues to make themselves available to review articles and to submit their reviews within the time allocated for this pivotal task. Without your support, there can be no journal. Because we realise that this is a selfless and often time-consuming task for which you receive little recognition, we wish to assure you that your support is greatly appreciated. We remind colleagues that reviewers will receive three CPD points for each article reviewed, one of which is for ethics.

Enjoy reading this issue of the $S A J P$.

\section{Kobus Maree}

\section{REFERENCES}

Bar-On, R. (2010). Emotional intelligence: an integral part of positive psychology. South African Journal of Psychology, 40, 54-62.

Elkonin, D.S., \& Sandison, A. (2010). Perceptions of registered counsellor efficacy. South African Journal of Psychology, 40, 90-96.

Lessing, A.C., \& De Beer, N.D. (2010). An interactionist model of self-concept and eating habits. South African Journal of Psychology, 40, 107-117.

Macleod, C.I., \& Tracey, T. (2010). A decade later: follow-up review of South African research on the consequences of and contributory factors in teen-aged pregnancy. South African Journal of Psychology, 40, 18-31.

Mpofu, E., Oakland, T., \& Gwirayi, P. (2010). Temperament styles in Zimbabwean early adolescents: a Rasch measurement model analysis. South African Journal of Psychology, 40, 44-53.

Pretorius, G., \& Pfeifer, N. (2010). Group art therapy with sexually abused girls. South African Journal of Psychology, 40, 63-73.

Samouilhan, T., \& Seabi, J. (2010). University students' beliefs about the causes and treatments of mental illness. South African Journal of Psychology, 40, 74-89.

Schrieff, L.E., Tredoux, C.G., Finchilescu, G., \& Dixon, J.A. (2010). Understanding the seating patterns in a residence-dining hall: a longitudinal study of intergroup contact. South African Journal of Psychology, 40, 5-17.

Thomas, K.G.F., Laurance, H.E., Nadel, L., \& Jacobs, W.J. (2010). Stress-induced impairment of spatial navigation in females. South African Journal of Psychology, 40, 32-43.

Van Staden, A. (2010). Comparing native signing, late-signing and orally trained deaf children's 'theory of mind' abilities. South African Journal of Psychology, 40, 97-106. 